MATEC Web of Conferences 37, 01012 (2015)

DOI: $10.1051 /$ matecconf/20153701012

C) Owned by the authors, published by EDP Sciences, 2015

\title{
ACCURACY ENHANCEMENT OF AUTOMATED SYSTEM FOR MULTICOMPONENT BATCHING OF BULK MATERIALS
}

\author{
V.G. Bukreev ${ }^{1, \text { a }}$, S.V. Lyapushkin ${ }^{1}$, M.M. Edgulov ${ }^{1}$ \\ ${ }^{1}$ National Research Tomsk Polytechnic University, Power-Engineering Institute, Electric Drive and Equipment Department, \\ 634050 Tomsk, Russia
}

\begin{abstract}
In the paper the choice of reasonable structure of automated system for multicomponent batching of bulk materials has been substantiated to minimize the batching error of about $3 \%$ in case the recipe mixture includes small components of big importance in terms of efficiency and cost. The algorithm of signal adaptation for weight controller of the electric drive control system of screw feeder, which takes into account the material properties changing and the "dropping column" mass.
\end{abstract}

\section{Introduction}

Systems of the bulk material batching are widely used in construction, food and pharmaceutical industries to make various mixtures. The main optimization criterion for such systems is the batching accuracy of each component of the recipe mixture, which is directly related to the material motion speed and other processing factors. Product quality is strictly regulated by the mixture production technology in the industries. The bulk material batching error is particularly important if components of high cost and small amount are used in the recipe mixture.

\section{Overview of batching systems for the bulk materials}

As feed mechanism of the material in automated system a screw feeder is considered. To fulfill the weight batching of the material with given feed of bulk goods a swinging dosing screw with weight sensor can be used. Zero reference point of the strain-gauge or piezoelectric weight sensor is set in prebalanced screw without the transported material. Advantage of this batching method is high accuracy, especially in continuously operating systems, since the weight of the material, which is located in the screw feeder, is measured instantaneously. As disadvantages of this method can be noted complexity of the mechanic system because of bellows decouplings in input and output orifices of the screw and increased sensitivity of the weight sensor to vibrations, which significantly worsen the calibration of the measuring part of the device.

Low reliability of the direct weight measuring sensors of the dosing screw made the small belt conveyor mounted on strain-gauge sensors to use as a device of instantaneous weight measuring . Such system is used in weight batchers to compose complex mixtures, where stability of the several components flow is maintained by instrumentation in pre-determined proportion [1]. Because of complexity of using the direct weight measurement systems a volumetric method of the screw batching is used without the weight sensor. In this case the screw feeder is a feeder with variable electric drive, which provides high accuracy of the screw speed. The volumetric method of the batching has error in measuring bulk weight, however the productivity of the volumetric feeders is ten times higher, than the weight feeders.

\footnotetext{
${ }^{a}$ Corresponding author : bukreev@tpu.ru
} 


\section{MATEC Web of Conferences}

To increase the accuracy of the volumetric screw feeders the batching with correction according to a given parameter has been used. As a version of technical realization of this approach a volumetric feeding system with correction of the screw speed according to the feed bin weight decreasing can be considered $[2,3]$. A subsystem of the component batching of the reaction mixture carries out the function of optimal feeding of its components to fulfill stoichiometric ratio. Information about the feed bin weight decreasing allows correcting the speed reference of the variable-speed electric drive of the batching screw to meet the requirements of the batching accuracy. However the disadvantages of such technological procedure are need to disable the speed correction of the screw feeder, when the feed bin is loaded by the material. In addition, if in the system there are several components of the mixture, then number of weighted feed bins and screw feeders is increased linearly.

Similar structure of multicomponent batching of bulk materials can be found in manufacturing procedures of feed mixtures in formula-feed mils. Main distinction of such systems is the discrete-portioning batching method of bulk materials. As striking example of such system can be considered automatic control system of batching the components of formula-feed and control of transportation and technological routes, which has been developed by enterprise «TeconTrade» (Moscow). Hardware of the complex of automated control system is realized based on industrial controller MFC 1500, personal computer under Windows XP and Ethernet; software - under ISaGRAF development environment and SCADA-system PcVue 10.0 [4]. This automated system has a number of advantages: simple and clear interface, timely indication of information about manufacturing process flowing and enhanced diagnostics of equipment. However wide use of the system is restrained by its high cost and difficulty in accuracy maintaining for small values of the mixture components.

\section{Automated complex of batching the bulk materials with variable- frequency electric drive of screw feeders}

The most reasonable principle of realization of the complex structure for the formula-feed production is to transport each component into common metering bin by individual screw feeders $[5,6]$.

Functional diagram of automatic system for batching the bulk materials with variable-frequency electric drive of screw feeders is shown in Fig. 1.

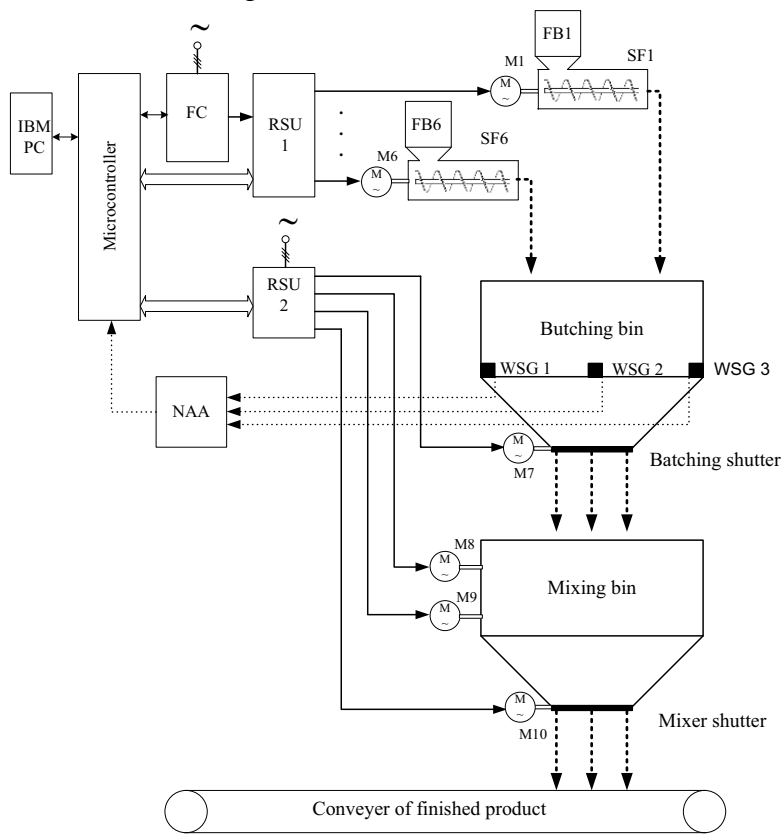

Figure1. Functional diagram of automatic complex for multicomponent batching 
In the diagram there are the following designations: FC- frequency converter; RSU - relay switching unit; NAA - normalizing adding amplifier; FB - feed bin; $\mathrm{MC}$ - microcontroller.

The equipment that produced the formula-feed consists of: 6 feed bins, which contain the components that have to be batched (barley, peas, wheat bran, wheat, sunflower meal, concentrate); 6 screw feeders; batching bin with handling capacity up to $1000 \mathrm{~kg}$, which is mounted on 3 weight strain gauges; blending hopper driven by electric induction motor of mixer of $15 \mathrm{~kW}$ power and by a motor of ripper; transport subsystem for finished products. The automation object includes ten induction motors of powers $1,7 \mathrm{~kW}$ to $15 \mathrm{~kW}$.

Required batching accuracy in such batching system is achieved by the weight control loop. Maximum operation speed of the loop is achieved due to that the weight controller is in saturation mode most of the batching time.

Because of the nonstationarity of the properties of the components that have to be batched, which influence greatly on the flowability of the material, the repeated batching with required accuracy tends to be a problem with no additional actions taken. To reduce the batching error a correction algorithm of the speed reference of the screw feeder drive based on statistical data is proposed to be implemented into the weight control loop and to maintain the productivity of the automated system on optimum level.

In Fig. 2. transients are shown for batching 1 kilogram of material without the speed reference correction based on statistical data, where final weight error equals to $0,191 \mathrm{~kg}$.

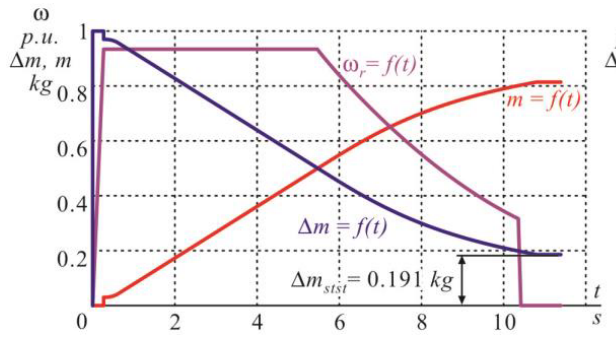

Figure 2. Transient of first cycle of batching

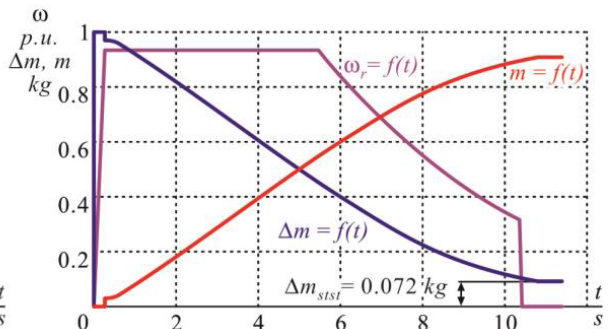

Figure 3. Transient with use of speed reference correction algorithm based on statistical data

When using the speed reference correction algorithm based on statistical data, the batching error is compensated roughly 2 -times (Fig. 3). Despite the improvement, the resulted error is $0,072 \mathrm{~kg}$ or $7,2 \%$ of the batched material mass, which is 2,4-times more, than is required according to regulations of the formula-feed preparation. For further decreasing the batching error down to $3 \%$ an algorithm of the mass compensation of the «falling column» of the material [6].

Results of simulation for batching $1 \mathrm{~kg}$ of bulk material are shown in Fig. 4. Joint use of the algorithms of the batching error correction based on statistical data and compensation of the error caused by weight of «falling column» decreases the batching error of the system no more that $2,7 \%$.

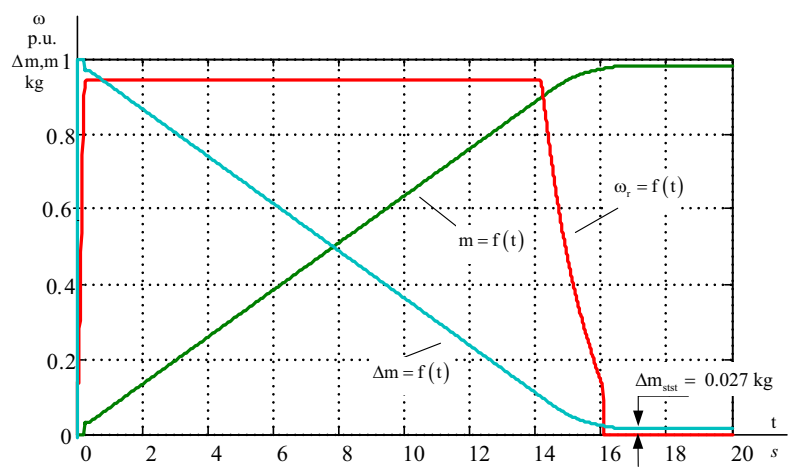

Figure 4. Transient for joint use of algorithms of the batching error correction 


\section{MATEC Web of Conferences}

\section{Conclusions}

Proposed structure of automated system of multicomponent batching allows to get cost-effective technical solution, in which increasing the batching accuracy of the components is achieved by using special algorithms of the system controller correction with common frequency converter of the electric drive for screw feeders.

Joint use of correction algorithms of batching error based on statistical data and compensation of the error caused by weight of «falling column» results in reducing the batching error down to less than $3 \%$, which corresponds to the production regulations of the formula-feed.

\section{References}

1. Katalymov A.V., Lyubartovich V.A. Dosing of bulk and viscous materials (Leningrad: Himiya, 1990)

2. Kladiev S.N.,Pishchulin V.P.,Dementiev Y.N. The 8th Russian - Korean International Symposium on Science and technology Proceedings, 1, 244 (2004)

3. Robkanov D.V., Dementiev Y.N., Kladiev S.N. The 8th Russian - Korean International Symposium on Science and technology Proceedings, 1, 280 (2004)

4. Automatic Process Control System dosing and mixing of feed and management of transport and technological routes of portion dosing and mixing. Access mode: http://www.tecon.ru/

5. Bukreev V.G. Automatic system of mixing and dosing bulk materials / Bukreev V.G., Gusev N.V., Nechaev M.A., Lyapushkin S.V. // Utility patent № 54179 (2006)

6. Bukreev V. G., Lyapushkin S. V., Gusev N. V. MATEC Web of Conferences. The $2^{\text {nd }}$ Intrnational Youth Forum «Smart grids», 19, 1 (2014) 